Article

\title{
The Role of Human Values and Relations in the Employment of People with Work-Relevant Disabilities
}

\author{
Lieke Kuiper ${ }^{1, *}$, Minne Bakker ${ }^{2}$ and Jac van der Klink ${ }^{3}$ \\ ${ }^{1}$ Health Sciences, VU University, 1081 HV Amsterdam, The Netherlands; E-Mail: I.m2.kuiper@student.vu.nl \\ 2 Department of Medical Humanities, VU University Medical Center, 1081 HV Amsterdam, The Netherlands; \\ E-Mail:mi.bakker@vumc.nl \\ ${ }^{3}$ Tranzo Scientific Center for Care and Welfare, Department of Social and Behavioral Sciences, Tilburg University, \\ The Netherlands; E-Mail: j.j.I.vdrklink@uvt.nl \\ * Corresponding author
}

Submitted: 21 June 2016 | Accepted: 26 September 2016 | Published: 10 November 2016

\begin{abstract}
The aim of this study is to discuss the role of human values and relations in the employment of people with work-relevant disabilities. Purpose: Finding and maintaining a paid job is known to be more difficult for people with a disability. The aim of the study is to explore the use which people with a disability make of their private and professional network in finding and maintaining a paid job and the role values play in these relations. This was placed in the context of three complementary perspectives: a perspective that stresses the importance of other than merely rationalistic values, a perspective that stresses the importance of values in work and an interpersonal perspective in which 'the Other' is central. Methods: Semi-structured interviews were held with 8 people with a working disability. As well, 4 interviews were held with people from their private network (family and partner) and 4 interviews with people from their professional network (colleagues and employers). All interviews were audio-taped and transcribed verbatim. A framework analysis was used to identify the different values in the interviews. This was done with use of MAXqda. Results: The interviews showed that both romantic and rational values and arguments were mentioned by the employers in the context of hiring people with a work-relevant disability; they need to be willing to adjust. The importance of human relations was emphasised in the values mentioned by the respondents when talking about having a paid job. Moreover, 'the Other' played an important role in the employment process of people with a work-relevant disability. People with such a disability asked their private network to help them and to provide emotional support. Conclusion: Enabling values and relations had more chance if they were in line with the mission and central value of the organisation. This was one of the first studies on the role that human values and relations play in maintaining a paid job for people with a work-relevant disability. The study gives a first impression of how human values and relations play a role, but more research is needed to provide more detailed insights, for example in different groups (e.g. non-employed people with a disability).
\end{abstract}

\section{Keywords}

disability; employment; human relations; values; work

\section{Issue}

This article is part of the issue "Humanity as a Contested Concept: Relations between Disability and 'Being Human'”, edited by Paul van Trigt (Leiden University, The Netherlands), Alice Schippers (Disability Studies in Nederland, The Netherlands) and Jacqueline Kool (Disability Studies in Nederland, The Netherlands).

(C) 2016 by the authors; licensee Cogitatio (Lisbon, Portugal). This article is licensed under a Creative Commons Attribution 4.0 International License (CC BY).

\section{Introduction}

In December 2006, a new rights based disability paradigm was set with the declaration of The United Na- tions Convention on the Rights of Persons with Disabilities. Within this paradigm, values such as dignity and human rights of people with disabilities have become more important. This paradigm presupposes a broader 
perspective on quality of life of people with disabilities; a perspective that goes beyond meeting the basic (care) needs, and focuses on social participation. This social participation could be enhanced via improved access to health, education or employment (Mahar, Cobigo, \& Stuart, 2013). Paradigms are important and presumably necessary, but certainly not sufficient for values, and subsequently behaviours, to be implemented in daily practice and (working) life. In the study reported in this article, we investigated values and value perspectives that people with a disability encounter in the workplace, facilitating or hindering their participation.

Maintaining a paid job can be difficult, especially for people with a work-relevant disability. In this article, we consider a disability to be work-relevant if it is a chronic disease, illness or disability, which may or may not be caused by work itself, but in all cases will impact the individual's functioning at work, indicating its relevance considering labour (Borst-Eilers, 1999). Employers generally expect more absenteeism and lower productivity from people with a work-relevant disability (Van Petersen, Vonk, \& Bouwmeester, 2004), which can make them reluctant to hire people with a disability (Winsemius \& van Houten, 2010). Insight is growing, though sporadically, that, on the other hand, hiring people with a work-relevant disability is one of the aspects of increasing workplace diversity (Ball, Monaco, Schmeling, Schartz, \& Blanck, 2005; Muyia Nafukho, Roessler, \& Kacirek, 2010). This diversity, in its turn, increases the creativity of the company by having different kinds of people in the organisation. A more diverse workforce attracts new customers and improves the company's or its brand's image (Vries et al., 2005).

Although the importance of work is widely acknowledged, the value of work is often described in terms of practical issues, such as income or daily structure. However, other values than income, such as building and maintaining meaningful relations and contributing to something valuable, play an increasingly important role for present day workers (Gheaus \& Herzog, 2016; Van der Klink et al., 2016), and this may count even more for people with a work-relevant disability. Indeed, the disability itself often leads towards a re-orientation on values, in which other values than income and career become important. There is often a need for more resources (like job control) too (Koolhaas, 2014; Koolhaas, Brouwer, Groothoff, Sorgdrager, \& Van der Klink, 2009), because people with a disability not only need to cope with their job demands but also with the demands of their condition.

Values of work can be regarded as governing interpersonal behaviour (Bardi \& Schwartz, 2003; Maio \& Olson, 1995; Taylor, 1989, 1992). Although issues related to the employment or not of people with a work-relevant disability have been largely researched, the role of values and their governing of interpersonal behaviour in the employment of people with a work-relevant disability have not been studied so far. Even so, to the best of our knowledge, there has been no research that inquires the role of the professional and private network of people with a work-relevant disability in their employment. Both perspectives, however, provide interesting insights in aspects playing a role in finding and maintaining a job for people with a work-relevant disability. Therefore, the aim of this study is to gain insight into how human values and relations play a role in the employment of people with work-relevant disabilities.

To achieve this aim we used three complementary but not mutually exclusive theoretical perspectives to approach our empirical data in a framework analysis: a perspective that stresses the importance of other than merely rationalistic economic values; a perspective that stresses the importance of values in work and an interpersonal perspective in which 'the Other' is central.

The first perspective is an overarching perspective that finds its roots in two contrasting societal views from different historical periods: rationalism and romanticism (Berlin, 1999; Van der Wilt, Deinum, \& Van Engelen, 2016). This perspective is inspired by the theoretical framework of Berlin. As he saw it, the Romantic revolution involved a rejection of the Rationalistic idea that (1) "all genuine questions can be answered," (2) "all these answers are knowable," and (3) "all these answers must be compatible with one another" (Berlin, 1999, pp. 21-22). This rationalism contrasts with the 'romantic' vision that the world is not organised by geometry but by poetry. Important values and goals cannot be 'discovered'; they have to be created. Romanticism asserts that also other values (driven by what is 'right' in a more moral way) are important and that values can be mutually conflicting (Berlin, 1999). Berlin states: "The notion that there are many values, and that they are incompatible; the whole notion of plurality, of inexhaustibility, of the imperfection of all human answers and arrangements; the notion that no single answer which claims to be perfect and true, whether in art or in life, can in principle be perfect or true-all this we owe to the romantics" (Berlin, 1999 p. 146). In our society, and especially in the economy and the labour market, values have predominantly been derived from a rationalistic point of view (efficiency, cost-effectiveness, etc.). The position of example is apt, because there are recent developments in economy and management that use a broader, 'romantic', value perspective than exclusively rationalistic values (corporate responsibility). Thus, in this broader perspective, the orientation on and the achievement of values that are outside the dominant (mainstream) rationalistic and economic values are central.

The second perspective can be seen as an elaboration of this: it is based on the values that people should be able to realise with their work and in their work. Throughout the history of philosophy from 'Aristotle to Arendt' people have thought about the value of human action and work. Mostly, at least three aspects are recognised: livelihood (making a living), creativity (creating something) and participation (being part of a com- 
munity). In this tradition Gheaus and Herzog (2016) recently identified four values people should be able to realise with work, besides income: (1) excellence, (2) social contribution, (3) community and (4) social recognition (Gheaus \& Herzog, 2016). Another modern value based framework is the capability approach developed by Amartya Sen $(1980,1993,2009)$. In this approach, people should be enabled to realise 'beings and doings people have reason to value'. According to Sen these values are group and context dependent and should not be formulated by experts but 'collected' in the target group in a democratic procedure. In this line, Van der Klink et al. (2016) identified and validated (Abma et al., 2016) seven work values in a population of Dutch workers: (1) the use of knowledge and skills, (2) the development of knowledge and skills; (3) involvement in important decisions; (4) building and maintaining meaningful contacts at work; (5) setting own goals; (6) having a good income; and (7) contributing to something valuable. Values are 'transformed to capabilities if they are important for a worker in his/her work situation and if $s /$ he is enabled and able to achieve the value in their work'. Thus, the context is essential. Within this perspective, in which the value people should realise with and in their work is central, the values Gheaus and Herzog identify are focused on what values should be achieved with work (work itself as a capability), while Van der Klink et al stress which values people should be able and enabled to achieve within their work (work capabilities).

The third perspective stresses the interpersonal perspective and is based on the theory of Levinas. After 2500 years of philosophy wherein either the self (egology) or 'being' (ontology) is central, Levinas introduces a totally different point of departure: the Other. A person is not determined by his or her self or by destiny, but by 'the Other'. Levinas' point of view may be elucidated by contrasting it with Sartre's view on the other. For Sartre, the discovery of the identity depends on others because "I can never see myself as others see me' (Sartre, 1943). The gaze of the other attributes characteristics to me that I cannot determine from myself, but it also 'objectifies' me and with that, I am reduced to a thing that is not subject to change. By that, the other denies me my freedom to act differently, to be different.

As Sartre relates the other to the self, Levinas takes a diametrically opposite starting point by placing 'The Other' in the central position and stating that human behaviour is determined by the responsibility towards 'the Other' (Levinas, 1961). For Levinas, 'the Other' is not knowable and should not be made into an object of the self, as is done by traditional philosophy that puts the self in the central position (from which either other people and the world can be objectified, or the other is considered as threatening the integrity of the self-as in Sartrian philsosophy). For Levinas, the responsibility for 'the Other' as a person is central and unconditional.

From this asymmetric relationship originates an ethical appeal. Ethics thus sprouts from my concern for 'The
Other'. Levinas outlines that freedom is predominantly a responsibility: my natural freedom becomes a moral freedom because I am invited to responsibility by the Other.

These three perspectives will be used in order to get insight into the motives for people with a work-relevant disability to work and the motives of employers to hire people with a work-relevant disability (or, in a broader context; the motives of the network to "invest" in people with a work-relevant disability).

\section{Methods}

\subsection{Study Design}

An exploratory qualitative network study was executed. This design was used to explore the views, opinions and attitudes of people with a work-relevant disability and their professional and private network, about their roles in the employment of people with a work-relevant disability and their motives and underlying values to do so.

\subsection{Recruitment}

Eight qualitative, semi-structured interviews with people with a work-relevant disability were conducted. Five people with a work-relevant disability gave permission to interview their private and professional related network as well, which led to another eight interviews. So, in total 16 interviews were conducted.

The eight people with a work-relevant disability were recruited from the networks of Emma at Work (employment agency for people with a work-relevant disability), Disability Studies in the Netherlands, Bartiméus (organization delivering services to visually impaired people) and the FNV (Federatie Nederlandse Vakbeweging), the largest trade union in the Netherlands. Participants were purposefully recruited. Inclusion criteria were: having a work-relevant disability and (experience with) a paid job. The people from the private and professional network were recruited by the primary interviewees (the persons with the work-relevant disability).

All participants were contacted via an e-mail in which the study objective was explained and their permission to be interviewed was formally requested. If they replied to the e-mail, they were subsequently called by phone. All optional participants who were contacted by phone enrolled in the study. During this phone conversation, both the study's objective and their permission to be interviewed were repeated, and an appointment was made for the interview.

\subsection{Data Collection}

Semi-structured, in-depth interviews were conducted with people with a work-relevant disability and the people from their private and professional networks. Interviews were conducted with the help of a topic list to increase the homogeneity between the topics spoken 
about in the interviews (Frambach, Van der Vleuten, \& Durning, 2013). The topic list was based on intuition and relevant themes suggested in the literature (Leufstadius, Eklund, \& Erlandsson, 2009). After each interview, the researcher evaluated the topic list to see if changes were necessary. The information collected from the initial interviews was used in the successive interviews. This led to new questions for the next interview(s), resulting in additional data generation (Van IJzendoorn, 1988). Important themes on the topic list were 'change as a result of getting a paid job', 'benefits a paid job can offer people with a work-relevant disability' and 'getting hired with a work-relevant disability'. The interviews were conducted either at the participants' home, at the office, or another quiet place to prevent disturbance.

\subsection{Data Analysis}

Based on the three complementary perspectives, a framework was formed to analyse the data. The key elements of each perspective were coded and these codes were assigned to text fragments in the transcripts. This was done with the use of a code book. The codes were noted as a priori codes in the codebook, provided with a separate label, definition and description for each code. The code book was designed by the researchers involved in the analysis, based on relevant literature considering the theories concerned. This led to a framework to structure and analyse the data in the transcripts in a meaningful way (Gale, Heath, Cameron, Rashid, \& Redwood, 2013). The interpersonal perspective, based on Levinas, with responsibility for 'the Other' as central theme was covered by three a priori codes: feeling responsible, showing responsibility and claiming responsibility. The society perspective based on Berlin was put into operation by eight a priori codes: being aware of, feeling and acting according to a 'rationalistic' value (costeffectiveness); the same triptych for 'not-rationalistic' or 'romantic', broader values and separate codes for incompatibility and incommensurability of these different viewpoints. The value perspective, as based on Gheaus and Sen/Van der Klink et al., was covered by 22 codes: the four values of Gheaus and the seven of Van der Klink et al were covered by two codes each: the importance of the value and the achievement of the value.
Each of the sixteen transcripts was analysed by two members of the research team. If a piece of text matched the description of one of the codes in the codebook, that piece of text was assigned to that code. For the analysis of the data, qualitative analysis software program MAXqda was used. In the phase of mapping and interpretation, the relationships between the concepts, typologies and associations with these concepts were explored (Green \& Thorogood, 2014). The differences and similarities between the views of the respondents were investigated. Finally, all findings were interpreted.

\section{Results}

\subsection{Participants}

The group of people with a work-relevant disability, who joined the study, consisted of six women and two men. They all were in the age range from 23 to 65 years old. They had different kinds of disabilities, illnesses or diseases, but all of them defined their disability as having impact on their work. One person currently did not have a paid job, but had experience with having a paid job (see Table 1). The interviews lasted on average $43 \mathrm{~min}-$ utes with a range between 26 and 83 minutes.

The people from the private and professional networks of those with a work-relevant disability consisted of six females and two males. They were between 28 and 66 years old (see Table 2 ).

Hereunder, various aspects of human values and relations in the context of employment are described. Three different theoretical perspectives were used to analyse the data, based on Levinas, Berlin and Gheaus/Sen as elaborated in the introduction. The reporting is structured based on these three perspectives. First, the results of the framework analysis of Levinas will be discussed, followed by Berlin and then Sen. All the results focus on the role of human relations as guided by values, in the employment of people with a work-relevant disability. Representative quotes are given in the text. Clues are added to indicate the source of the quotation ( $R$ refers to a person with a work-relevant disability. $C$ refers to people from the private or professional network. See Tables 1 and 2 for more details about the respondents).

Table 1. Demographic information about the participants with a work-relevant disability.

\begin{tabular}{lllll}
\hline & Sex & Age & Type of disability & Paid job \\
\hline R1 & Female & 26 & Chronic disease & Administrative assistant \\
R2 & Female & 26 & Psychiatric disability & Administrative job during the summer \\
R3 & Female & 43 & Chronic disease & None \\
R4 & Female & 48 & Sensory disability & Freelancer, CEO, member of several Supervisory Boards \\
R5 & Female & 28 & Physical and mental disability & Sheltered work \\
R6 & Male & 38 & Psychiatric disability & Sheltered work \\
R7 & Female & 65 & Sensory and mental disability & Sheltered work \\
R8 & Male & 52 & Sensory disability & Psychosocial supporter at the county \\
\hline
\end{tabular}


Table 2. Demographic information about the participants who were part of the private and professional network of the interviewees with a work-relevant disability.

\begin{tabular}{lllll}
\hline & Sex & Age & Connection & Paid job \\
\hline C1.1 & Female & 46 & Supervisor R1 & Manager \\
C1.2 & Female & 25 & Colleague R1 & Project coordinator \\
C1.3 & Female & 56 & Mother R1 & Nurse \\
C1.4 & Male & 28 & Brother R1 & Social media agent \\
\hline C2.1 & Female & 59 & Commissioner R2 & Director \\
C2.2 & Male & 63 & Partner R2 & Program manager, strategic adviser \\
\hline C6.1 & Female & 36 & Head of the HRM department of R6 & Head of the HRM department \\
C6.2 & Female & 66 & Friend R6 & None \\
\hline
\end{tabular}

\subsection{Moral Perspective}

In this perspective, inspired by the work of Berlin, the central viewpoint is that people in an organisation often cherish a broader set of values than those that are strictly in line with the 'rationalistic' organisational goals (maximise profit and (cost-)effectiveness).

Employers use both rational and non-rational 'romantic' arguments when discussing the employment of a person with a work-relevant disability. This shows thatalthough both types of arguments seem contrary-they do not necessarily exclude one another. All three employers mentioned the importance of accessibility and inclusiveness. The importance of accessibility is the most expressed 'romantic' value by the employers interviewed. As people with a work-relevant disability have trouble finding and maintaining a job, the employers feel an urge to help them. They feel responsible for the people with a work-relevant disability as well as feeling responsible for society as a whole.

The employers emphasize that people with a workrelevant disability are part of society, a society with a labour market that is not accessible and inclusive for people with a disability. The employers want to contribute to the solution, to change society and make it more inclusive for people with a disability. They acknowledge that a better world starts at home and, therefore. they want to be part of the solution, not of the problem.

"We have an important role in society in general and want to set an example for society. This means giving people who have fewer chances in life opportunities as well." (C1.1)

Another important value, which played a role in employing people with a work-relevant disability, is the importance of a pleasant working atmosphere. This is not necessarily related to the disability as such, but to the attitude of the employee with the disability. Working hard, being a good colleague and being willing to contribute to the company and its working atmosphere are important reasons to hire and employ someone with a workrelevant disability.
A positive attitude, sometimes rooted in gratitude for getting opportunities and a job, can improve the working atmosphere and working culture, resulting that people from the professional network experience the providing of help to the people with a work-relevant disability less as a burden than as a commitment towards a respected colleague.

"I think she delivers a positive contribution to the working culture by the way she is standing in life." (C1.1)

However, in some cases the rational argument of costeffectiveness outweighed the broader 'romantic' values. This implies a hierarchy in which 'romantic' values are restricted to a certain limit value. They can be used to argue for a certain investment in the employee, but this investment is not infinite, neither in time, nor in money. The employers in our sample drew a line under to what extent they could invest in people with a disability. They found it hard to make this explicit, as there is not a strict criterion for the worth of romantic values. However, all the employers stated that there is such an imaginary line, which can change over time and from case to case. Nevertheless, there is a limit.

"Look, if we needed to invest in a 10.000-euro computer for a task of three months, we would have solved it differently [and not have employed her]." (C4.2)

On the other hand, romantic and rational values can reinforce each other. Sometimes the romantic value of creating a pleasant working atmosphere results in more costeffectiveness. Supervisors use these kinds of rational arguments to convince their superiors of the importance of 'romantic' values.

"I think the working culture is determining the way you approach the people you meet, so by setting R1 as an example and learning from her positive attitude we will probably change the way we approach our clients for the better, which will be beneficial for the company." (C1.1) 


\subsection{Value Driven Perspective}

In this perspective, the value people should realise with and in their work is central. The work values as according to the capability approach and the values formulated by Gheaus and Herzog may represent values from an individual or personal perspective. For people with a workrelevant disability, several of these values are overtly related to human relations. Not all values will be discussed; hereunder, the focus will be on values which were most frequently mentioned and/or had a striking, different meaning in the group of people with a workrelevant disability. Four of the 'capabilities' (the development of knowledge and skills; building and maintaining meaningful contacts at work; having a good income; and contributing to something valuable), and three of the values of Gheaus will be presented (being part of a community, excellence and social recognition) (Gheaus \& Herzog, 2016) .

\subsubsection{The Development of Knowledge and Skills}

This value not only represents the development or growth in itself, but rather the respondents express that they feel that they were given a chance by their employer or colleague to grow and evolve in their jobs. In general, the respondents express gratitude for the opportunities given by their professional network. To some respondents, getting this opportunity is more important than the actual personal growth or development. This reflects the essence of the concept of capability in which the opportunity to achieve is central and not the actual performance (that can depend on-restricted-choice).

"My self-esteem has grown, because I got the chance to learn and got some education in the meantime. They do not see me as a hopeless case. That is really valuable to me." (R1)

\subsubsection{Building and Maintaining Meaningful Contacts at Work}

Being surrounded by other people is described as an important aspect of work by almost all people with a workrelevant disability. Having a paid job gives them the opportunity to meet new people. Making connections gives them the feeling that they are (still) valuable. People who have been unemployed for a certain amount of time, who are living in an institution and/or have a small group of friends or social contacts describe even more benefits of having a paid job than people who had a large private network. They have been feeling lonely for a certain amount of time and the gain of not being on their own but being able to connect on a regular basis was tremendous for this group.

People who have had a paid job for quite some time make use of the connections made. They use their professional network to create new chances. Moreover, they mention that some people from their professional network became part of their personal network as well. Some people were still friends with people who had been their colleagues years before.

"I: What has having a job given you - what would you not get if you didn't have a job?

R: Friends" (R2)

The social part of work was recognised as important by the professional and private network of the people with a work-relevant disability as well.

"You are actually doing something that you like, also aimed at socializing, for example, which sounds very much like getting through the day." (C1.3)

This value seems to be particularly important for people with a work-relevant disability; because of their diminished energy, it is very difficult to maintain a social network beside their work.

\subsubsection{Having a Good Income}

Remarkably, income was not mentioned by all respondents as a value of work (where this is one of the explicitly mentioned values in work for non-disabled (Abma et al., 2016; Jahoda, 1982)). For these respondents, other values such as social contact, structure or social contribution are the reasons to work. For some respondents, however, their income is of great value. Not so much because of the possibilities it gives them to buy material things, but rather because it gives them freedom and independence. Not relying on the government or partner/parents gives them a feeling of freedom.

"When I had enough financial security and a cell phone and a credit card, I was able to manage every situation. I did not need my eyes that badly anymore." (R4)

"To keep that independency, because there were times when I was really depending on my parents, I was not working because of my disease, and that didn't feel well." (R2)

This is in line with how the ancient Greek looked at the relation between work and income. Work performed to earn a living was very low esteemed, not much higher than slavery, but work that served a higher goal like independency or freedom or a societal goal, was highly esteemed (Van der Klink, 2015).

\subsubsection{Contributing to Something Valuable}

When people with a disability are not able to work, they receive social benefits in The Netherlands. This means a basic income is guaranteed for them. However, earning 
their own money gives most respondents the opportunity to repay society. Society gave them an income when they were not able to earn it themselves; now they want to contribute to society, by earning their own money and repay it by paying taxes. Besides paying taxes, a contribution is made by producing goods or providing services which are beneficial to others, as pointed out by some respondents. Being able to contribute strengthens their identity and their role in society.

"[Work means] really doing something for society to get money" (C6.1)

"[About making sockets] I am really useful for someone else. Socket, well, if you don't have power you can't do a lot of things. Take a kettle, you need a socket. A stove needs power as well. So many things need power. Think about a vacuum cleaner, a fridge, a freezer, a washing machine, you can go on and on and on. If there is no power, if there are no sockets, all those things are not useful anymore." (R6)

The notion that work is more than an economic transaction and should add (other) values for the worker and for society is a reflection of the ancient Greek perception mentioned above and of the broader 'romantic' perspective.

\subsubsection{Being Part of a Community}

Having someone with a work-relevant disability in the workforce is only possible in a community that is willing to adjust. People with a work-relevant disability do sometimes need some special care. This can imply going on sick leave more often than people without a workrelevant disability, but can also imply taking the elevator instead of the stairs or making sure the hallway is empty to prevent someone with a visual disability from hitting boxes which stand in the way and falling. This need for adjustments means that the other people in the company need to take the person with a work-relevant disability into account. Adaptation has to be reciprocal.

It is normal in a company that people have to take their colleagues into account; however, the people with a work-impacting disability, their colleagues and employers, when interviewed, declare this happens on a more regular basis for people with a work-relevant disability. The willingness to change your behaviour to help someone in the community was seen as an obligation and not as a choice, because you are helping the wider community and not only the person who receives help. Admitting someone into the community means reaching goals as a group.

"I am not worried about being absent, my colleagues know about it [having a work-relevant disability], if the work that needs to be done is urgent they will work it out. It gives me a safe feeling, them knowing that [needing to adjust]." (R1)
The respondents are, in general, well aware of their dependence on others, also considering their job. Some try to prevent difficulties, by putting extra effort into building a network that could forestall problems. They are conscious about their sometimes fragile position and building a network or safety net can partly overcome this fragility.

\section{"I: How does such a network arise?}

R: By building it reeeeeeally carefully, investing lots and lots of time, attention, being seriously interested, being careful. Keeping in touch with all those people, remembering birthdays, asking about their wives, that kind of simple stuff, letting them know you exist, on Facebook, on Twitter, on Instagram, whatever, Linkedln of course." (C.1)

This value shows a divergence of perceptions. From the perspective of the 'community', having a person with a work-related disability as a member can contribute to the diversity and development of the group. From the perspective of the person with the work-relevant disability, however, it appears to be a value on the 'safety level' with the function of a life vest or safety net.

\subsubsection{Excellence}

Having a work-relevant disability means people have to overcome all kinds of boundaries, every single day. These boundaries imply that working is more of a challenge for them than for their colleagues who do not have a disability. By not giving up hope and keeping their heads up, people with a disability are set as an example for and by their colleagues and employers. Their positive attitude to face every challenge is seen as a contribution to the work in which they excel and that is sometimes deliberately used to change the working climate.

Feeling appreciated for their hard work and being able to influence the company is giving a boost to the self-esteem of people with a work-relevant disability. It makes them more loyal to their colleagues, their employer and their company as well. It therefore strengthens their will to keep working despite all the challenges.

"It's wonderful to hear colleagues say: 'Gosh, you know, I think about the things I do' or 'I complain less about aches, because you suffer every day.' Wow, those are the things that make me realise one's personality can make a tremendous difference in a department or a company." (R1)

The downside of the fact that being able to keep up, to act 'normal' and not complain, is that some people with a disability have the feeling that in order to be accepted they are not allowed to complain or at least not too much. This can be troubling for some of them. Besides, the type of recognition based on their positive attitude is experienced as difficult and frustrating by some respondents. 
They do not want recognition based on their disability, but rather based on their (professional) capacities and work. In their attempt to be 'normal', they sometimes feel uncomfortable to accept this type of recognition.

"Every time I had to overcome boundaries, because I was young, because I was not able to see well, that made me think: 'Fuck you, I will not play the part you want me to'. I do not like to carry a stigma with me.... I did not come this far by pointing at my disability. If I have a problem, I need to solve it." (R4)

For this target group, the value of excellence is not so much applicable to the 'output' of work, the product, but rather to the 'throughput', the mode of carrying it out.

\subsubsection{Social Recognition}

The fact that people with a work-relevant disability perform in a paid job, leads to different kinds of appreciation by the people surrounding them. First of all, there is the recognition of the boundaries people with a disability have to face by the people from their professional network, as discussed above. Secondly, having a paid job changes the way society feels about people with a workrelevant disability as well. People with a disability often feel less valued based on experiences through their lives of having been bullied or denied a job because of their disability. Paid work changes, for some of them, their role in society. It is important for these people to be acknowledged in their capacities, to be valued as a 'normal' human being, to be part of society.

"Her bullies are all stay-at-home mums at this point and she is travelling the world, she outranked them all in some way. She did not go to her school reunion. First she did, wanted to go and show them: 'Look here I am, I am having a life of my own'. But they are not worth it." (C4.1)

The interviews show that being recognised as "having a life of their own', acting and performing like everybody else is an important recognition for people with a workrelevant disability.

\subsection{Interpersonal Perspective}

In this perspective, being responsible for 'the Other' is central. The definition of 'the Other' is based on Levinas: the Other as a subject that cannot be objectified nor controlled.

Having a paid job can be exhausting for people with a work-relevant disability. This means they explicitly or implicitly demand their private network to take this into consideration. They expect their private network not to exclude them when they do not have the energy to join them or the energy to be cheerful when they get home. Moreover, people with a work-relevant disabil- ity ask their private network to spare them and dismiss them from household tasks. They need the support and collaboration of the people from their private network to hold their job. Besides that, the emotional support, the willingness to adjust and the pride expressed by people from their private network gives the people with a disability firmness and a feeling of having a safety net and being able to take a risk and try to excel.

People with a work-relevant disability appeal to their private and professional network to take responsibility and to see their colleague not merely as instrumental but as a source.

This reflects the categorical imperative by Kant but is specifically concordant with the conception of 'the Other' according to Levinas. The interviews show that this conception plays a very important role in the employment process of people with a disability.

"My mum is a big support, she will always back me up, she is really proud of me. [It influences my work] It makes me feel positive to know there are always people [like mum] happy with my being." (R1)

The professional network needs to accept the person with a work-relevant disability, who in most cases differs from the general workforce, as 'the Other' and take responsibility for him/her. This means the workforce needs to be open-minded to change itself and to accept and adapt to the person with a work-relevant disability. It is therefore necessary that there is a focus on the need to adapt and adjust the work environment to make it possible for the person with a work-relevant disability to become-and stay-part of the professional network. Therefore, it is necessary to focus not solely on the Otherness but ask about the needs of the person with a work-relevant disability and the need to adjust. The focus should be on the need to change the working atmosphere. By being willing to adjust, the person with a workrelevant disability is not only Another but becomes part of the professional network as an 'Other'.

"Everyone has to take that [R1 being frequently absent] into account, the tasks assigned to her have to be tuned on that [R1 being absent sometimes]....This means her colleagues have to know about it, accept and adjust." (C1.1)

\section{Discussion}

\subsection{Summary of the Results}

The results give insight into how human values and relations play a role in the jobs of people with work-relevant disabilities. Both romantic and rational values and arguments were mentioned by both employees and employers in the context of employing people with a workrelevant disability. These values can reinforce each other but can also be incompatible. With regard to specific 
work values, there seem to be some differences in the appreciation of these values compared with people without a work-relevant disability. Because this was not a comparative study, this observation must be considered with caution. The importance of human relations was emphasised in the values mentioned by the respondents, when talking about having a paid job. The interviews showed that 'the Other' plays a very important role in the employment process of people with a work-relevant disability. People with such a disability, appeal to their professional network for consideration and practical support and to their private network to help them and to provide emotional support. Both networks need to be willing to adjust.

In this article, three different perspectives were used to gain a deeper insight into the value of human relations in work for people with a work-relevant disability. The three perspectives have in common that they all stress the importance of a broader value perspective than a just self-centred economic perspective. They differ in how the individual level interacts with the context. The moral perspective focuses on the morality, on the basis of the acts of the individual in a societal context, the value driven perspective focuses on the values of work for the individual in his or her micro-, meso- and macro context (Van der Klink et al., 2016) and the interpersonal perspective focuses on the responsibility of the individual from and to the individual 'Other'.

We chose these three perspectives because of their complementary characteristics. For the moral, societal perspective, we chose Berlin because he devoted his professional work to 'a strikingly audacious project: to define Western philosophy as a single coherent tradition based upon a faith in rationality, to convince us that such faith is unwarranted-even dangerous - and to advance his own ideas to take its place.' (Sylva, 1999). Our choice for Sen's capability approach was motivated by the increasing importance and influence of this value driven approach in many fields and because of the recent operationalization for work (Abma et al., 2016; van der Klink et al., 2016). The recently formulated values of Gheaus and Herzog were added because of their complementarity. Levinas was chosen because he was undoubtedly the thinker with the most extreme position regarding our responsibility towards the Other, a beacon that is probably unreachable but can show us the direction.

Sen and Levinas both underline the importance of responsibility. For Levinas, this is predominantly an appeal to the individual: your responsibility for 'the Other' is a personal responsibility. For Sen the responsibility is both individual and societal: people have a societal claim to be enabled to achieve their capabilities. Levinas and Berlin also have a common focus on responsibility as a 'romantic' value. For Levinas, this responsibility is a very specific appeal of the individual 'Other'. The employers in our sample stressed that they felt, besides their responsibility towards the individual employee with a workrelevant disability, a responsibility to society too. This is more in line with Berlin. Sen's capabilities might be seen as a translation to a specific context of Berlin's broad scope on values that should not be merely rational. However, Sen would object to the distinction rationalistic versus not rationalistic. In one of his most influential essays, he analyses the economic literature from Smith to Edgeworth and notes that the precise formalising of selfinterest as an economic principle is an irrational misconception (Sen, 1977). Sen argues that the 'rationalistic' economic man is significantly worse off because of a failure to recognise the distinction between actual individual preferences and our ethical ideals:

"A person thus described may be 'rational' in the limited sense of revealing no inconsistencies in his choice behaviour, but if he has no use for these distinctions between quite different concepts, he must be a bit of a fool. The purely economic man is indeed close to being a social moron." (Sen, 1977)

For people with a work-relevant disability, the context seems even more important and relevant. The relationships with their private and professional network play an important role in the meaning that the values of work become relational values. This was found in every perspective.

The relationship between the individual and the concept of 'the Other' is a reciprocal one. People with and without a work-relevant disability feel, answer and ask responsibility of each other. 'The Other', as Levinas describes, is not allowed to be objectified and integrated in the self; you have to leave him or her 'the Other', in the sense that you owe him/her responsibility and respect as a person, a separate identity on its own (Levinas, 1961). The interviews show that the private and professional networks are demanded-and willing-to change and act out of responsibility towards the person with a work-relevant disability, designated as 'the Other'. Our results showed that this 'Other' tries to make a change too, feeling responsible to 'return' or 'repay' by being 'a model employee'. By that, it is meant that being responsible for 'the Other' is conditional. There has to be a reciprocal relationship with 'the Other' to feel responsible for 'the Other'. Here, practice as reflected in our interviews does not meet one of the cornerstones of Levinas' theory: that the responsibility for 'The Other' is unconditional. By imposing conditions on the responsibility for 'the Other', that 'Other' loses its role as the centre of attention. Even the good practices we investigated could not meet the high ethical standards of Levinas. Notwithstanding, the data are in line with seeing 'the Other' as a separate identity and not merely instrumental as contributor to rational goals. As such, the data are in line with Kant's categorical imperative. This imperative was meant as a moral guideline, a practical philosophically based rule. Levinas does not make the claim of a moral imperative. He designates his point of view as 'first philosophy', prior to practical ethics. This leaves the possi- 
bility to consider Levinas' description of the Other as a regulative ideal, a beacon, something to strive for with as highest achievable operationalization as Kant's categorical imperative.

According to our material, romantic and rational values can be sometimes incompatible or hierarchical. When the cost to fulfil a romantic non-rational value exceeded a certain limit, the romantic value went down. This confirms the presumption that there is a certain limit to which the romantic value is seen as achievable and that, in the present work, rational values must in the end prevail. Romantic values can have a place but that place is limited by rationalistic borders.

Values such as 'Having a good income' or 'Contributing to something valuable' seem, for people with a workrelevant disability, especially meaningful in the context of the relationships with their private and professional networks. In the case of people with a work-relevant disability, there is a strong interaction between, on the one hand, the private and professional network and society as a whole and, on the other hand, these personal values. The values that guided the relations and, vice versa, were almost all values that were affected by the way other people conceived people with a disability. This seems specific for people with a work-relevant disability.

Besides that, values can have a different meaning for the people with and without a work-relevant disability. Earning an income, for instance, is one of the values identified by people without a disability to work (Abma et al., 2016; Van der Klink et al., 2011). People with a workrelevant disability valued an income more because of the independency it gave, than because of getting an income as value in itself. This may relate to the fact that they would receive a benefit if they did not work, but the independence from others and the pride in being self-sufficient were strong (interpersonal) values in themselves.

The product of their labour is, in contrast to people without a work-impacting disability, not the main indication of the excellence of people with a work-relevant disability. Being able to contribute to the working process, to a company and to society by having a paid job and acting 'normal' and, despite the disability, not being inferior to colleagues without a work-relevant disability is a way of being excellent when you have a disability. Some interviewees with a disability even managed to be excellent at setting an example of how to cope with problems. In general, considering the capability perspective of which "'being" people and "doing" people have reason to be valued" is an important aspect. For people with a work-related disability, it seems the 'being' aspect is more important than the 'doing' identity. Being a 'normal', valuable and valued person is even more important than doing all the things you value.

\subsection{Methodological Strengths and Limitations}

Semi-structured, in-depth interviews as data gathering method combined with a framework analysis fitted the aim of this study and the research question but, as in every qualitative research, the results are not meant to be generalised. The research population consisted of an appropriate sample of people with a work-relevant disability, which led to a diverse group of people. There were relatively large proportions of females, people with a sensory disability and people with a mental disability. Although the ages of the study population varied, there were three people in their forties, three people in their twenties, but none in their early thirties. Around the age of thirty, people are making decisions about having children or not, therefore important insights may have been missed. Two of the respondents (R3 and R4) spoke about the difficulty of combining a paid job and having a disability. They both derived a different conclusion from this dilemma: R3 decided to stop working and R4 decided not to have children to be able to hold on to her job. It could have been interesting to interview someone who was in his or her early thirties and was deciding if he or she wanted to have children or not.

The COREQ-checklist was used to ensure all important aspects of this research were reported (Tong, Sainsbury, \& Craig, 2007). The research fell short in two of the 32 criteria of this checklist; namely, data saturation and participant checking. Although data saturation was accomplished within the respondents group of people with a work-relevant disability, data saturation was not accomplished within the respondents group from the professional networks nor in the group of respondents from the personal networks of the primary respondents. This could mean that there might be additional values relevant. However, all values included in the framework were mentioned in the interviews, which implies that we gained a broad insight into the meaning of these values and their differences.

Neither the transcripts nor the results were sent to the participants meaning that there might have been an unrectified mistake in the transcripts. Input from the participants might have given some extra information that could have enriched the results found.

To the best of our knowledge, this is the first research on values and relations with respect to people with a work-relevant disability. This makes this research innovative, but also a proper comparison with other studies is more or less impossible.

\subsection{Implications and Conclusion}

People with a work-relevant disability need adjustments in order to work. The paradigm mentioned at the beginning of this article, secures the rights of people with a disability on these adjustments and on participation. This study investigated which value systems exist in daily working situations that could serve as a matrix for the implementation of these rights. The perspectives we used showed to be useful in structuring and interpreting our data. Employers who valued the romantic value of accessibility, inclusiveness and creating a better work- 
ing atmosphere as a rational value were willing to take the needs of the people with a disability into account. They felt responsible for the fact that employees with a work-relevant disability could achieve the value of having work and important values in that work. We found that 'enabling values and relations' had more chance if they were in line with the mission and central value of the organisation.

A practical application of this study might use the help it provides us to select the right arguments if we want to introduce a person with a work-relevant disability for employment. With employers that are receptive for only 'rationalistic' arguments, we should choose Sen's strategy of an alternative rationality: it is rational to strive for diversity and a fit of values of the company and its employees and to meet societal standards of responsibility. When dealing with employers that have a broader value perspective, a more direct appeal to the responsibility can be made.

This was one of the first studies on the role that human values and relations play in maintaining a paid job for people with a work-relevant disability. The study gives a first impression of how human values and relations play a role, but more research is needed to provide more detailed insights, for example in different groups (e.g. non-employed people with a disability). Further research can provide more insights that policy makers and the government can use to improve the work participation of people with a work-relevant disability.

\section{Acknowledgements}

Thanks are due to Paul van Trigt, Jacqueline Kool and Alice Schippers, for early discussions on this topic and the chance to take part in this special issue. Also thanks to the two anonymous reviewers for their comments on an earlier draft of this paper.

\section{Conflict of Interests}

The authors declare no conflict of interests.

\section{References}

Abma, F. I., Brouwer, S., De Vries, H. J., Arends, I., Robroek, S. J. W., Cuijpers, M. P., ... Van der Klink, J. J. (2016). The capability set for work: Development and validation of a new questionnaire. Scandinavian Journal of Work, Environment and Health, 42(1), 34-42.

Ball, P., Monaco, G., Schmeling, J., Schartz, H., \& Blanck, P. (2005). Disability as diversity in Fortune $100 \mathrm{com}-$ panies. Behavioral Sciences and the Law, 23(1), 97121. doi:10.1002/bsl.629

Bardi, A., \& Schwartz, S. H. (2003). Values and behavior: Strength and structure of relations. Personality and Social Psychology Bulletin, 29, 1207-1220.

Berlin, I. (1999). The roots of romanticism. Princeton, NJ: Princeton University Press.
Borst-Eilers, E. (1999). Beleidsvisie inzake kenniscentra voor arbeidsrelevante aandoeningen, (48), 19.

Frambach, J., Van der Vleuten, C., \& Durning, S. (2013). Quality criteria in qualitative and quantitative research. Academic Medicine, 88(4), 552.

Gale, N. K., Heath, G., Cameron, E., Rashid, S., \& Redwood, S. (2013). Using the framework method for the analysis of qualitative data in multi-disciplinary health research. BMC Medical Research Methodolog, 13(117), 1-8.

Gheaus, A., \& Herzog, L. (2016). The goods of work (other than money!). Journal of Social Philosophy, 47(1), 7089. doi:10.1111/josp.12140

Green, J., \& Thorogood, N. (2014). Qualitative methods for health research (3rd ed.). London: SAGE Publications.

Jahoda, M. (1982). Employment and unemployment: A social-psychological analysis. London: Cambridge University Press.

Koolhaas, W. (2014). Sustainable employability of ageing workers-The development of an intervention. Rijksuniversiteit Groningen.

Koolhaas, W., Brouwer, S., Groothoff, J., Sorgdrager, B., \& Van der Klink, J. J. L. (2009). Bevorderen van de duurzame inzetbaarheid van de oudere werknemer. Langer doorwerken gaat niet vanzelf. Tijdschrift Voor Bedrijfs- En Verzekeringsgeneeskunde, 17(7), 286291.

Leufstadius, C., Eklund, M., \& Erlandsson, L. K. (2009). Meaningfulness in work-Experiences among employed individuals with persistent mental illness. Work, 34(1), 21-32. doi:10.3233/WOR-2009-0899

Levinas, E. (1961). Totalité et Infini: Essai sur l'extériorité. La Haye: Nijhoff.

Mahar, A. L., Cobigo, V., \& Stuart, H. (2013). Conceptualizing belonging. Disability and Rehabilitation, 35(12), 1026-1032. doi:10.3109/09638288.2012.717584

Maio, G. R., \& Olson, J. W. (1995). Relations between values, attitudes, and behavioral intentions: The moderating role of attitude function. Journal of Experimental Social Psychology, 31(3), 266-285.

Muyia Nafukho, F., Roessler, R. T., \& Kacirek, K. (2010). Disability as a diversity factor: Implications for human resource practices. Advances in Developing Human Resources, 12(4), 395-406. doi:10.1177/ 1523422310379209

Sartre, J. P. (1943). L'être et le néant. Paris: Editions Gallimard.

Sen, A. (1977). A critique of the behavioral foundations of economic theory. Philosophy \& Public Affairs, 6(4), 317-344.

Sen, A. (1980). Equality of what? In S. McMurrin (Ed.), The Tanner lectures on human values. Salt Lake City: University of Utah Press.

Sen, A. (1993). Capability and well-being. In M. Nusbaum \& A. Sen (Eds.), The quality of life. Oxford: Oxford University Press.

Sen, A. (2009). The idea of justice. London: Allen Lane. 
Sylva, D. A. (1999). Book review "The roots of romanticism." New York Times.

Taylor, C. (1989). Sources of the self. New York: Cambridge University Press.

Taylor, C. (1992). The ethics of authenticity. Cambridge: Harvard University Press.

Tong, A., Sainsbury, P., \& Craig, J. (2007). Consolidated criteria for reporting qualitative research ( COREQ ): A 32-item checklist for interviews and focus groups, 19(6), 349-357.

Van der Klink, J. J. L. (2015). Value at work: Sustainable employability as capability; a multidisciplinary perspective. Inaugural lecture. Tilburg University.

Van der Klink, J. J. L., Bültmann, U., Burdorf, A., Schaufeli, W. B., Zijlstra, F. R. H., Abma, F. I., ... Van der Wilt, G. J. (2016). Sustainable employability-Definition, conceptualization, and implications: A perspective based on the capability approach. Scandinavian Journal of Work, Environment and Health, 42(1), 71-79. doi:10.5271/sjweh.3531

Van der Klink, J. J. L. Van Der, Bültmann, U., Brouwer, S., Burdorf, A., Schaufeli, W. B., Zijlstra, F. R. H., \& Wilt, G. J. Van Der. (2011). Werk als waarde. Gedrag \& Organisatie, 2011(24), 342-356.

Van der Wilt, G. J., Deinum, J., \& Van Engelen, B. (2016). The value of life [De waarde van het leven]. In T.
Wobbes \& M. den Muijsenbergh (Eds.), The Euro in the consulting room. Money does play a role [De euro in de spreekkamer. Geld speelt wel een rol] (3rd ed.). Annalen van het Thijmgenootschap.

Van IJzendoorn, M. H. (1988). De navolgbaarheid van kwalitatief onderzoek I: methodologische uitgangspunten. Nederlands Tijdschrift voor Opvoeding, Vorming en Onderwijs, 4(5), 280-288. Retrieved from http://openaccess.leidenuniv.nl/bitstream/handle/1 887/1417/168_082.pdf?sequence=1

Van Petersen, A., Vonk, M., \& Bouwmeester, J. (2004). Onbekend maakt onbemind: Attitude onderzoek naar de positie van arbeidsgehandicapten op de arbeidsmarkt. 09-01-2004. Leiden. Retrieved from http:// www.uitgeverijbetelgeuze.eu/pdf/Onbekend_maakt onbemind.pdf

Vries, S. De, Ven, C. Van De, Nuyens, M., Stark, K., Van Schie, J., \& Van Sloten, G. C. (2005). Diversiteit op de werkvloer: hoe werkt dat? Hoofddorp. Retrieved from http://www.studentcontent.nl/documenten/ Arbeidsmarktdynamiek/diversiteit_op_de_werkvloer _hoe_werkt_dat.pdf

Winsemius, A., \& van Houten, M. (2010). Participatie ontward. Utrecht. Retrieved from https:// www.movisie.nl/sites/default/files/alfresco_files/Par ticipatie ontward\%5BMOV-222582-0.3\%5D.pdf

\section{About the Authors}

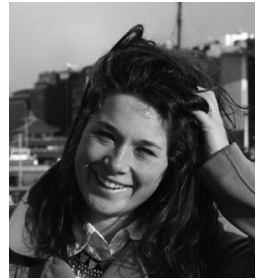

Lieke Kuiper is a student of Health Sciences and Philosophy at the Vrije Universiteit Amsterdam. She holds a bachelor's degree in Health Sciences and a bachelor's degree in Philosophy. She likes to combine both research fields to get a broader perspective on the subject of study. As well as this, she likes to use the views of different 'stakeholders' to get a clearer view on the research subject.

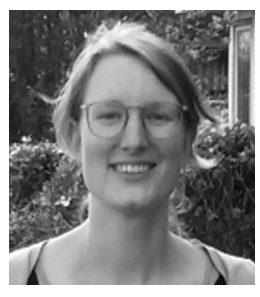

Minne Bakker is a researcher at the Department of Medical Humanities, VU Medical Centre in Amsterdam. In her research, Minne is interested in the participation of people with disabilities. She has a PhD degree in Medical Sociology. The patient perspective is very important in all her studies. Besides being a researcher, Minne is a teacher in Medical Sociology, qualitative research methods and medical ethics.

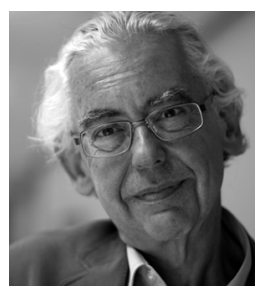

Jac van der Klink is professor of mental health at work and sustainable employability at Tranzo, the scientific centre for care and welfare at the Tilburg School of Social and Behavioural Sciences, Tilburg University. He was professor of Occupational Health at UMC Groningen from 2006 until 2014. He is a strategic advisor at the Netherlands School of Public and Occupational Health (NSPOH) and Ascender, a provider of work-related consultancy and care in the mental health and sustainable employability field. 